\title{
PIERRE BOURDIEU: A HERANÇA SOCIOLÓGICA
}

\author{
Maria Drosila Vasconcellos*
}

\begin{abstract}
RESUMO: Através de uma apresentação, em ordem cronológica, da obra de Pierre Bourdieu, tentou-se extrair as idéias, os elementos teóricos e os conceitos elaborados por ele. Começando com um trabalho de campo na Argélia, ele desenvolveu pouco a pouco um sistema de explicação sociológica da dominação social. A escola, a cultura, a economia foram, entre outros, estudadas aplicando conceitos novos na sociologia, tais como habitus, violência simbólica ou campo social. Propondo uma nova leitura das relações sociais, Bourdieu criou um modo de pensar suscitando criticas severas, mas também uma obra profícua utilizada nos mais variados setores sociais.
\end{abstract}

Palavras-chave: Herança social. Reprodução social. Habitus. Violência simbólica.

\section{Pierre Bourdieu: The Sociological inheritance}

ABSTRACT: Through a chronological presentation of Bourdieu's work, we tried to extract his ideas and the theoretical elements and concepts he formulated. Beginning his fieldwork in Algeria, he gradually developed an explanatory system of social domination. School, culture, economy have been studied, among others, under the application of such new sociological concepts as habitus, symbolical violence or social field. Proposing a new reading of the social relationships, Bourdieu created a way of thinking used in various social sectors that aroused as many criticisms as fruitful researches.

Key words: Social inheritance. Social reproduction. Habitus. Symbolical violence.

Professora da Université Lille 3 (França). E-mail: vasconcellos@wanadoo.fr 

presentar a obra de Pierre Bourdieu não é uma tarefa fácil: ele é sem duvida um dos grandes sociólogos do século XX, reconhecido internacionalmente. Elaborando, obra por obra, um sistema completo de leitura das relações sociais, ele criou uma verdadeira "escola" que contribuiu à reflexão crítica em torno do seu trabalho. É verdade que poucos sociólogos lidaram com um vasto campo da sociedade francesa como espaço de dominação, cujos mecanismos estão dissumulados. Para ele, o papel do sociólogo é o de desvendar o que se passa "por de trás do pano".

Engajado no debate público, Pierre Bourdieu é o sociólogo que conheceu a consagração científica e a do grande público. Todavia, sua obra é ainda mal conhecida. $\mathrm{O}$ objetivo deste artigo é fornecer uma visão panorâmica de sua obra por meio de suas publicações, na tentativa de extrair a riqueza das idéias e dos debates que ela suscitou. Entretanto, as dificuldades da apresentação são grandes, devido à densidade dessa obra, englobando assuntos os mais variados: campesinato, artistas, escola, bispos, patronato, política, consumo, cultura, mídia etc.; e também à utilização de disciplinas variadas, introduzindo novas interrogações em cada uma delas (Sociologia, Antropologia, Etnologia, Filosofia, Lingüística, Economia, Historia, entre outras). Na impossibilidade de fazer um resumo temático, pois todo recorte seria sempre arbitrário, podendo amputar a obra de temas importantes, a escolha foi da apresentá-la por ordem cronológica. Embora discutível, esta abordagem cronológica pode fornecer certas referências biográficas e bibliográficas ao leitor.

\section{A preponderância da herança}

Bourdieu obteve o diploma de Filosofia na Escola Normal Superior, considerada instituição de maior prestígio na área dos estudos de letras e filosofia e de onde saíram Jean Paul Sartre, Simone Beauvoir, A. Camus, $\mathrm{R}$. Aron e outros intelectuais de após-guerra. Apesar de sair de uma escola considerada no topo máximo da consagração, Bourdieu não se deixa encantar como tantos outros da sua geração ou da anterior. Devendo cumprir o serviço militar em plena guerra da Argélia, ele exerce neste país o professorado. Contudo, logo se interessa pela situação da agricultura argelina, porque na passagem de um sistema tradicional ao capitalismo moderno, o campesinato está em plena transformação naquele país. Neste período de crise ele se associa a Abdelmaleck Sayad, a fim de estudar a emergência do capitalismo e as transformações no "espírito" da organização social e política da sociedade argelina. Esse trabalho comum 
que se inicia nos anos 60 só terminará com o desaparecimento de Sayad. E um período profícuo para Bourdieu, que escreve uma profusão de obras cujas publicações aparecem posteriormente: Sociologia da Argélia (1958), Argélia ano 60 (1977), Le Déracinement (1964), Trabalbo e trabalhadores na Argélia (1963). Nesta última, Bourdieu desenvolve um dos conceitos-chave de sua teoria, marcando profundamente a sociologia tanto para utilizá-lo como para criticá-lo: o conceito de habitus. $\mathrm{O}$ artigo sobre o "Celibato e a condição camponesa" (1962) revela o mecanismo sutil que transforma as modalidades de reprodução social e biológica. E a análise dos "arranjos" familiares que fazem do casamento uma forma de sobrevivência no sistema de relações sociais e econômicas. O interesse desse artigo está também na comparação que ele efetua entre esse sistema de "arranjos" familiares na Kabilia (Argélia) e no Béarn, sua região natal. Como em varias conferências ou textos, Bourdieu considera que ele se torna verdadeiramente sociólogo e etnólogo pela experiência argelina. Até em sua última aula no Colégio de França, ele evocará fatos ou idéias que nasceram nessa época e que marcaram toda sua teoria.

Assim, o conceito de habitus que ele desenvolverá ao longo da sua obra corresponde a uma matriz, determinada pela posição social do indivíduo que lhe permite pensar, ver e agir nas mais variadas situações. O habitus traduz, dessa forma, estilos de vida, julgamentos políticos, morais, estéticos. Ele é também um meio de ação que permite criar ou desenvolver estratégias individuais ou coletivas.

Voltando à França, Bourdieu torna-se assistente na Universidade de Lille e, em 1964, é eleito professor na atual Ecole des Hauts Etudes en Sciences Sociales. Começa um período intenso de trabalhos sobre o ensino universitário em colaboração com Jean Claude Passeron. Ambos eram filósofos e tornaram-se sociólogos como alunos de Raymond Aron. E ambos põem em dúvida uma das idéias mais tenazes da ideologia republicana: a igualdade de oportunidades e a importância do sistema escolar para garantir igualdade social a todos. É o próprio fundamento da sociedade meritocrática que eles criticam e o sistema de ensino considerado como a ponta de lança dessa ideologia. Eles apresentam Les Héritiers (1964) na editora Minuit, na qual Bourdieu dirigirá a coleçao "Le sens commun", onde vários autores estrangeiros ou franceses se tornarão conhecidos no campo das ciências sociais. Nesta obra, os autores chamam a atenção para a relação entre o "capital cultural”, a seleção social e escolar. O conceito de capital cultural (diplomas, nível de conhecimento geral, boas maneiras) é utilizado para se distinguir do capital econômico e do capital social (rede de relações sociais). Os 
estudantes de classe média ou da alta burguesia, pela proximidade com a cultura "erudita", pelas práticas culturais ou lingüísticas de seu meio familiar, têm mais probabilidades de obter o sucesso escolar. "O que Bourdieu demonstra é que existe relação entre a cultura e as desigualdades escolares: a escola pressupõe certas competências que são de fato adquiridas na esfera familiar” (Baudelot, 2002).

Esta relação entre o ensino e a cultura inspira uma serie de publicações sobre as funções sociais das práticas culturais. No livro L'art moyen (1965), o primeiro que escreve sobre a cultura e particularmente sobre a fotografia, em colaboração com L. Boltanski, R Castel, J. C. Chamboredon. Em seguida é L'Amour de l'art (1966), em colaboração com A. Darbel e D. Schnapper, no qual Bourdieu estuda a freqüência aos museus. A idéia de unir esses dois universos - educação e cultura é a origem da criação do Centro de Sociologia da Educação e da Cultura (1968), onde ele trabalhara até 1981, quando entra no Colégio de France.

Desde a criação deste centro de pesquisa, ele escreve, com J. C. Passeron e J. C. Chamboredon, o livro Le métier de sociologue (1968), que marcará várias gerações de sociólogos. Nele, através da apresentação de textos escolhidos, esforça-se para romper com o "senso-comum" e desenvolver um "espírito científico".

O sucesso de Os herdeiros e as críticas que recebe, sobretudo do meio de professores ou de responsáveis pelas instâncias políticas, fazem com que ele se interesse em analisar as modalidades de funcionamento interno do sistema de ensino. Bourdieu e Passeron elaboram uma obra importante em sociologia da educação, tanto pelas afirmações que propõem quanto pelas críticas que eles sucitam. Cabe relembrar que a obra La Reproduction (1970) contém um subtítulo importante "Elementos para uma teoria do sistema de ensino". Contrariamente à idéia mais divulgada que faz da escola um reflexo e um instrumento da reprodução social, a obra da Reprodução tenta desenvolver a noção da violência simbólica. De fato, ele expõe aí os determinismos e a força da coação social, o que causa inúmeras críticas, principalmente no meio professoral (sindicatos, associações etc.).

Através do uso da noção de violência simbólica ele tenta desvendar o mecanismo que faz com que os indivíduos vejam como "natural" as representações ou as idéias sociais dominanantes. A violência simbólica é desenvolvida pelas instituições e pelos agentes que as animam e sobre a qual se apóia o exercício da autoridade. Bourdieu considera que a transmissão pela escola da cultura escolar (conteúdos, programas, métodos 
de trabalho e de avaliação, relações pedagógicas, práticas lingüísticas), própria à classe dominante, revela uma violência simbólica exercida sobre os alunos de classes populares.

A partir de um conceito de "chave mestra", que é o da dominação que recobre formas variadas de relações de poder, Bourdieu focaliza a forma a mais insidiosa exercida pela violência simbólica. No livro sobre Les héritiers ele releva que o sucesso escolar é condicionado à origem social dos alunos e, assim, torna-se o primeiro a revelar os mecanismos cognitivos ligados às condições sociais. O termo violência simbólica aparece como eficaz para explicar a adesão dos dominados: dominação imposta pela aceitação das regras, das sanções, a incapacidade de conhecer as regras de direito ou morais, as práticas lingüísticas e outras.

Pierre Bourdieu elabora, assim, um sistema teórico que não cessará de desenvolver: as condições de participação social baseiam-se na herança social. O acúmulo de bens simbólicos e outros estão inscritos nas estruturas do pensamento (mas também no corpo) e são constitutivos do habitus através do qual os indivíduos elaboram suas trajetórias e asseguram a reprodução social. Esta não pode se realizar sem a ação sutil dos agentes e das instituições, preservando as funções sociais pela violência simbólica exercida sobre os indivíduos e com a adesão deles.

\section{O desenvolvimento da crítica social}

Ao longo dos anos 70, Bourdieu se dedica a várias pesquisas sobre o processo de diferenciação social, visando elaborar uma teoria geral das classes sociais. La distinction (1979) aparece como síntese desse período e é considerada, por vários autores, como obra central na carreira sociológica de Bourdieu. Com um subtítulo importante "Crítica social do julgamento", ele tenta construir a correspondência entre práticas culturais e classes sociais assim como ao princípio que legitima a hierarquia aí implícita.

A ambição do autor é construir uma teoria sociológica das categorias que organizam a percepção do mundo social. Contrariamente a idéia tradicional da sociologia de que as práticas culturais são objeto de consenso, na medida em que elas

significam o reconhecimento de valores comuns definindo uma civilização e levam à integração nesta civilização e à sociedade que a conduz, a análise da distinção mostra, ao contrário, que elas são um meio de classificar, que elas implicam uma batalha perpétua para tomar iniciativa, para se afirmar, para se colocar socialmente. (Reynaud, 2002) 
Através da critica social ao gosto estético, Bourdieu afirma que a arte popular não consegue aceder a nenhuma legitimidade estética, mas ela serve de "referência negativa" à arte superior ou consagrada.

Os julgamentos de gostos, de preferências não são o reflexo da estrutura social, mas um meio de afirmar ou de conformar uma vinculação social. Na Distinção, ele expõe duas idéias centrais e originais. De um lado, as relações de poder como categoria de dominação são analisadas pela metáfora do capital cultural no qual se apóia o principio de reprodução social. De outro, o entrecruzamento das relações de poder com as várias formas de ações organizadas favorece a capacidade dos indivíduos para elaborar estratégias que, todavia, não ultrapassam as relações de desigualdades sociais.

Desde o começo dos anos 70, Bourdieu se propõe a elaborar uma teoria da sociologia da ação. A publicação da Esquisse d'une théorie pratique (1971) constitui o prenúncio de seu importante livro sobre Le sens pratique (1980). Esta é uma nova versão da sua teoria sobre a economia das práticas, procurando situar a sociologia em relação à corrente objetivista simbolizada pela etnologia de Claude Levi-Strauss e às correntes subjetivistas representadas pela fenomenologia de J. P. Sartre.

Ao mesmo tempo ele tenta aplicar o esquema de análise utilizado para o sistema de ensino para transpô-lo a outros sistemas sociais, estendendo assim o campo da sua produção sociológica: arte, ciências, moda, literatura, economia, filosofia etc. Esta intensa produção sociológica o leva a fundar uma nova revista Actes de la Recherche en Sciences Sociais (1975), que renova o estilo das publicações científicas pela introdução de fotografias, de encartes, e da maquete.

No bojo dessa produção, um novo conceito aparece: o campo social. No artigo sobre "Le marché dês biens savants" (1971), Bourdieu propõe as bases da análise do campo da produção, introduzindo a distinção entre a produção "erudita" restrita, visando o público produtor de idéias e seus próprios concorrentes. Ele evoca o campo artístico e o da produção cultural (jornalístico ou indústria da cultura) destinados ao público em geral. No artigo sobre a "Especificidade do campo científico e as condições sociais do progresso da razão" (1975), ele introduz os conceitos de campo e de capital científico, rompendo com a tradição sociológica dominante na sociologia da ciência e da "comunidade científica". Bourdieu mostra que a lógica de mercado, intrínseca a todo tipo de produção, está presente também no da ciência que, sem ser submetida a uma clientela direta, confronta-se com os desafios da concorrência interna, entre pesquisadores. 
Os anos 80 constituem uma mudança importante na produção e na ação de Bourdieu. Em 1981, eleito ao Colégio de France, ele cria a cátedra de sociologia na mais prestigiosa das instituições de ensino e de pesquisa francesa.

De um lado, ele publica vários livros que constituem uma iniciação à sua obra, às vezes, de acesso difícil aos neófitos: Question de sociologie (1980), Choses dites (1987), Réponses (1992) e Raisons pratiques (1994). De outro, ele publica vários livros a fim de explorar campos precisos na sociedade. Assim, apoia-se em trabalhos de filósofos analíticos da linguagem, como Austin, para propor um livro sociolingüístico, Ce que parler veut dire (1982), no qual ele desenvolve uma análise dos enunciados performativos: quando dizer é fazer.

Aliás, Bourdieu criou um estilo literário nas ciências sociais: criticado pela complexidade dos textos, pela utilização de um vocabulário que repulsa os neófitos, ele afirma que "só se pode pensar corretamente através da análise de casos empíricos teoricamente construídos". No entanto, alguns dos conceitos que desenvolveu fazem parte hoje do vocabulário corrente de sociólogos ou dos que trabalham sobre o social (violência simbólica, campo, capital cultural etc.). De uma certa forma, é a reafirmação do que escreve no livro Réponses: "mudar as palavras ou as representações é transformar as coisas.” Seu estilo literário, pretensamente elitista, está diretamente ligado a este combate.

Ainda no começo dos anos 80 , ele trabalha sobre o campo universitário, o campo do jornalismo, o campo literário etc. A noção de campo representa para Bourdieu um espaço social de dominação e de conflitos. Cada campo tem uma certa autonomia e possui suas próprias regras de organização e de hierarquia social. Como num jogo de xadrez, o indivíduo age ou joga segundo sua posição social neste espaço delimitado.

Na sua obra Homo academicus (1984), Bourdieu estuda os professores das universidades, mostrando a organização do espaço universitário, a luta entre as várias disciplinas e o academismo do corpo professoral.

Em seguida, ele volta-se à analise das "grandes escolas", uma característica do ensino superior na França, pois elas preparam os funcionários de alto nível da esfera do poder. Pela seleção severa que efetuam no recrutamento dos alunos, elas são verdadeiras instituições 
de elite, quase nunca referenciadas quando se estuda o ensino superior francês, focalizando-se apenas as universidades. Dedica-se a essas grandes escolas que são apresentadas no livro La noblesse d'Etat (1989), onde ele analisa os mecanismos que conduzem uma pequena fração de filhos da alta burguesia a freqüentar essas instituições, desde a escolaridade secundária e ainda a longa e intensa preparação aos quais eles são submetidos. Este esforço é recompensado pela carreira de sucesso que é assegurada pela obtenção do diploma e da classificação ao exame final. Tal estudo das "grandes escolas" conduz Bourdieu a se interessar pelo funcionamento geral do Estado, que foi objeto de seminários no Colégio de France e de vários artigos na sua própria revista.

O campo da literatura também constituiu um vasto trabalho através do qual ele tentou mostrar a importância da revolução simbólica iniciada no mundo das letras e a função social dos intelectuais. É expressiva desta área de estudos a publicação de Les règles de l'art (1992), cujo subtitulo é, uma vez mais, esclarecedor: "Gênese e estrutura do campo literário".

O inicio dos anos 90, na França, foi marcado pelo agravamento da crise econômica, do emprego e pela emergência do fenômeno da exclusão social. Diante desses processos, Bourdieu mobiliza um número importante de sociólogos do centro de estudos que havia criado e outros que se associam a suas idéias e, através de numerosas entrevistas recolhidas junto a um público variado (alunos de colégios situados em bairros de periferia de população de baixa renda, jovens desempregados, educadores ou assistentes sociais, professores, diretores de colégios, juízes, médicos, policiais, entre outros), ele elabora uma crítica ao neo-liberalismo. O resultado é um livro de quase 1000 páginas consagrado à La misère du monde (1993). O sucesso da obra ultrapassa o campo sociológico, transformando-se em objeto de debate na esfera política ou na mídia. Alguns trechos serão tema de teatralização, principalmente junto ao público que é analisado. Várias noções que aparecem neste livro entram no vocabulário de sociólogos como "os excluídos de dentro", que caracterizam os alunos ou jovens trabalhadores e desempregados discriminados por suas origens (étnicas, sociais, culturais, geográficas). Uma vez mais Bourdieu mostra a hipocrisia da sociedade francesa republicana e meritocrática, na qual se afirma que a igualdade de oportunidades é assegurada a todos pelo Estado.

Começa então um período de engajamento politico, quando Bourdieu suscita por um lado críticas no meio intelectual e, por outro, 
ganha projeção na mídia. As greves de novembro e dezembro de 1995 fazem de Bourdieu um dos principais defensores das reivindicações e animador do Movimento Social recém-criado. O slogan "à esquerda, todos!" contribui para fazer de Bourdieu um símbolo da "esquerda da esquerda”, um movimento crítico da esquerda liberal que investe o poder.

Simultaneamente, ele trabalha num livro de inspiração filosófica no qual põe em perspectiva o conjunto da sua obra: Méditations pascaliennes (1997). Em seguida, seu livro sobre a Dominação masculina (1998) representa sua contribuição ao trabalho sobre gênero.

E, finalmente, o livro sobre Les structures sociais de l'économie (2000), no qual apresenta uma crítica à ciência econômica que se torna hegemônica e dominante na sociedade atual.

O engajamento político de Bourdieu nos anos $90 \mathrm{faz}$ com que ele crie uma coleção de livros visando alimentar os debates sociais e ideológicos: Les raisons d'agir, na qual o numero "Sur la television” (1996) é um sucesso de livraria tanto na França quanto no estrangeiro. O suplemento "Líber" da revista Actes de la Recherche en Sciences Sociais torna-se também uma tribuna de expressão de autores estrangeiros sobre os diversos modos de dominação social.

Distinguindo-se pela elaboração de uma teoria e de uma reflexão singular sobre a prática sociológica, ${ }^{1}$ Pierre Bourdieu promoveu a revelação do social e se dispôs a desvendar os mecanismos mais íntimos de construção da sociedade. Como intelectual engajado, ele é sempre comparado a Sartre ou a Foulcaut. No entanto, em várias ocasiões, Bourdieu se referiu a Jean Jacques Rousseau como símbolo do intelectual: de aprendiz de relojoeiro em Genebra, ele revolucionou a literatura social, inventando novos conceitos em filosofia política. Sendo o único escritor clássico francês que não teve origem burguesa ou aristocrática, ele foi rejeitado por todos os intelectuais da época. Rousseau, entretanto, criou um modo de intervenção do filósofo no mundo social, pelo combate contra "as desiguldades entre os homens".

Recebido e aprovado em abril de 2002.

\section{Nota}

1. É o tema do filme realizado por Piere Carles sobre a obra de P. Bourdieu, A sociologia é um esporte de combate, Paris, 2000. 
Referências bibliográficas

BAUDELOT, Ch. "Le scandale des héritiers", Les Inrockuptibles, Dossier Pierre Bourdieu (1930-2002), Paris, fév. 2002, n 323.

BOURDIEU, Pierre. Sociologie de Algérie. Paris : PUF, Coll. Que saisjé?, 1958.

. Célibat et condition paysanne. Etudes Rurales, avril-septembre 1962, n 5/6.

. Travail et travailleurs en Algérie. Paris-La Haye: Mouton, 1963.

. Les héritiers. Paris: Ed. de Minuit, 1964.

. Le déracinement. Paris : Ed. de Minuit, 1964.

. L'amour de l'art. Paris: Ed. de Minuit, 1966.

. Le métier de sociologue. Paris: Mouton-Bordas, 1968.

. La reproduction. Paris: Ed. de Minuit, 1970.

. Le marché dês biens symboliques. L'Année sociologica. Paris: PUF, 1971.

. Esquisse d'une théorie de la pratique. Paris: Mouton-Bordas, 1971.

. La spécificité du champ scientifique et les conditions sociais du propre de la raison. Sociologie et Sociétés, Montréal, avr. 1975.

. Le champ scientifique. Actes de la recherche en sciences sociales. Paris: Ed. du Seuil, 1976.

. Algérie, année 60. Paris: Ed. de Minuit, 1977.

. La distinction. Paris: Ed. de Minuit, 1979.

. Le sens pratique. Paris: Ed. de Minuit, 1980.

- Questions de sociologie. Paris: Ed. de Minuit, 1980.

. Ce qui parler veut dire. Paris: Ed. de Minuit, 1982.

. Choses dites. Paris: Ed. de Minuit, 1987.

. Homo academicus. Paris: Ed. de Minuit, 1984.

. Les règles de l'art. Paris: Ed. du Seuil, 1992. 
. Réponses. Paris: Ed. du Seuil, 1992.

. La misère du monde. Paris: Ed. du Seuil, 1993.

. Raisons pratiques. Paris: Ed. du Seuil, 1994.

. Sur la télévision. Paris: Liber-Raisons d'Agir, 1996.

. Les méditations pascaliennes. Paris: Ed. du Seuil, 1997.

. La domination masculine. Paris: Ed. du Seuil, 1998.

. Les structures sociales de l'économie. Paris: Ed. du Seuil, 2000.

. Science de la science et réflexivité. Paris: Liber-Raisons d'agir, 2001.

REYNAUD, J.D. Hommage a P. Bourdieu. Revue Française de Sociologie, jan.-mars 2002, n 1. 